\title{
A One-year Retrospective Study on the Pattern of Death Found at Autopsy at Forensic Pathology Department, Menelik II Hospital in Addis Ababa, Ethiopia.
}

\author{
E E Solano ${ }^{1}$, Y O Mayedo ${ }^{2}$, M Seyoumk ${ }^{3}$ \\ ${ }^{1}$ Head, Department of Forensic Pathology. Menelik II Hospital. AddisAbaba. \\ Ethiopia. \\ ${ }^{2}$ specialist of Legal Medicine. Menelik II Hospital. Addis Ababa Ethiopia. \\ ${ }^{3}$ Associate Professor of Surgery. Head, Department of Surgery. Menelik II \\ Hospital. Addis Ababa. Ethiopia. \\ Correspondence to: M Seyumk, Email:seyoumkassa@gmail.com \\ https://dx.doi.org/10.4314/ecajs.v22i1.13
}

Background: The main objectives of this study were to determine the magnitude, manner and modalities of natural and unnatural deaths among deaths brought to the Forensic Pathology Department. Menelik II Hospital, for post mortem examination and secondary to find the remedial measures that may have influence on the incidence of preventable deaths.

Methods: This retrospective study was conducted in the Department of Forensic Pathology at Menelik II Hospital, Addis Ababa, Ethiopia. From January $1^{\text {st }}, 2014$ to December 31 ${ }^{\text {st }}$, 2014.

The Study material was collected from Forensic Pathology Department of Menelik II Hospital, postmortem reports. A total of 4206 cases of deaths were done postmortem examination during the one-year study period. All these cases were grouped according to age, gender, manners and modalities of natural and unnatural deaths. The data collected was analyzed.

Results: Out of total 4206 cases, the male to female ratio 3:1. The age group most commonly involved was $16-30$ years $(41,5 \%)$ followed by $31-55$ years $(38,3 \%)$. Only $7.8 \%$ were in the under 15years age group. The commonest mode of death in all age groups put together was accident in 1615 (38.4\%) followed by natural death in 1156 (27.5\%), homicidal deaths accounted for 698 (16.6\%) followed by suicide in 508 (12\%). In 229 (5.4\%) of the cases the manner of death remained undetermined. Among 698 homicidal deaths, blunt weapon injury accounted for $61.4 \%$ and bullet injury were in $15.4 \%$. Among the accidental deaths, road traffic injuries were 1092 (67.6\%), followed by fall accident in 170 (10.5\%). Hanging was the preferred modality of suicide (88.4\%), followed by poisoning 51 (10\%). Natural death accounted for 1190 (27.5\%) and cardiac disease was the most predominant 453 (38\%), followed by respiratory disease 240 (20.2\%).

Conclusion: Our study concludes that unnatural deaths exceeded enormously the natural deaths. Accident was the most dominant manner of death among the unnatural deaths. Road Traffic Accident was the commonest modality among accidental deaths. Fatalities caused by blunt weapon injuries were the commonest mode of homicide; whereas hanging was the preferred modality of suicide. Cardiovascular diseases were the leading 


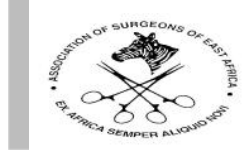

causes of natural deaths. Most deaths are preventable, so concerned bodies are expected to take action of prevention and increase the public awareness of the real situation and the causes of both natural and unnatural deaths and subsequently make an impact in the decrement of death rate in our societies.

\section{Introduction}

Death is a tragedy in whatever form, at whatever time and in whatever way it comes ${ }^{1}$. The death is natural when it is due to any pathology (disease) or ageing, and is unnatural when caused prematurely against order of the nature by injury, poison or other means of violence. Unnatural deaths may be accidental, suicidal, homicidal or undetermined. The data of unnatural deaths may reflect the law and order situation in a particular area of jurisdiction ${ }^{2}$. If Death is premature, unexpected and resulting from violence causes harassment / depression not only among the relatives of deceased but also have certain impacts all over the society ${ }^{3}$.

Every Human being is blessed with the gift of life for the purpose of being happy and to bring peace for all but the purpose is ignored when human pursuit of wealth and power, satisfaction of physical appetites, and passions terrorize their fellow human beings. The crime and violence exist in the society since long over the centuries but in this modern era there is an extreme aggravation of these problems ${ }^{4}$. Drawing public attention and awareness towards casualties is important to prevent unnatural deaths; this possibly could reduce the incidence of such cases.

This study was not only aimed at finding out the magnitude of natural and unnatural deaths but also to provide information of the demographic profile, manners and modalities involved in deaths, presented to the Department of Forensic pathology of Menelik II Hospital, for post mortem examination. The finding of this study will create awareness among the people about deaths related to violence, which is the important public health concern in the society. It will also be helpful for law enforcement agencies to make the strategies for prevention of such incidences.

Emperor Menelik II was fascinated by modernity, and like Emperor Tewodros II before him had a keen ambition to introduce Western technological and administrative advances into Ethiopia. The Russian support for Ethiopia led to the advent of a Russian Red Cross mission. The Russian mission was a military mission conceived as medical support for the Ethiopian troops. It arrived in Addis Ababa some three months after the historic Menelik's Adwa victory $1^{\text {st }}$ of March 1896 (26) and then the first hospital, (Menelik II) was created in Ethiopia.

Menelik II Hospital is currently the only hospital where forensic pathology service is provided, this being the reason for the large amount of deaths received in the center in a period of one year.There are two Legal Medicine specialists working in the department on a full time basis. Both professionals are among the authors of this study. To our knowledge this is the first study of its kind from the department and the country and we hope this will 


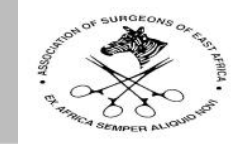

give insight on the magnitude of the reality and would serve as a basis for other studies to come.

\section{Materials and Methods}

This study was undertaken on on 4206 death subjects brought to Department of Forensic

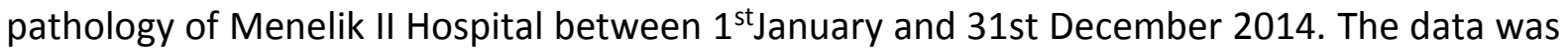
collected from the hospital notes / treatment history and Medico-legal certificates hospital notes included age, gender and treatment history. The information about circumstances of death was sought from the police inquest reports. The data was entered on a Proforma, statistically analyzed and the results were summarized in charts.

Ethical Considerations: Permission was obtained from Head of the Department of Forensic pathology, Menelik II Hospital, for examining the relevant data required for this study.

\section{Results}

Out of the total 4206 deaths, 698 (16.6\%) cases were due to homicides and 1615 (38.4\%) of accidents while 508 cases (12\%) were involved in suicidal deaths. In 1156 (27.7\%) cases, the manner of death was natural, whereas manner of death in 229 (5.4\%) cases was undetermined (Figure 1).

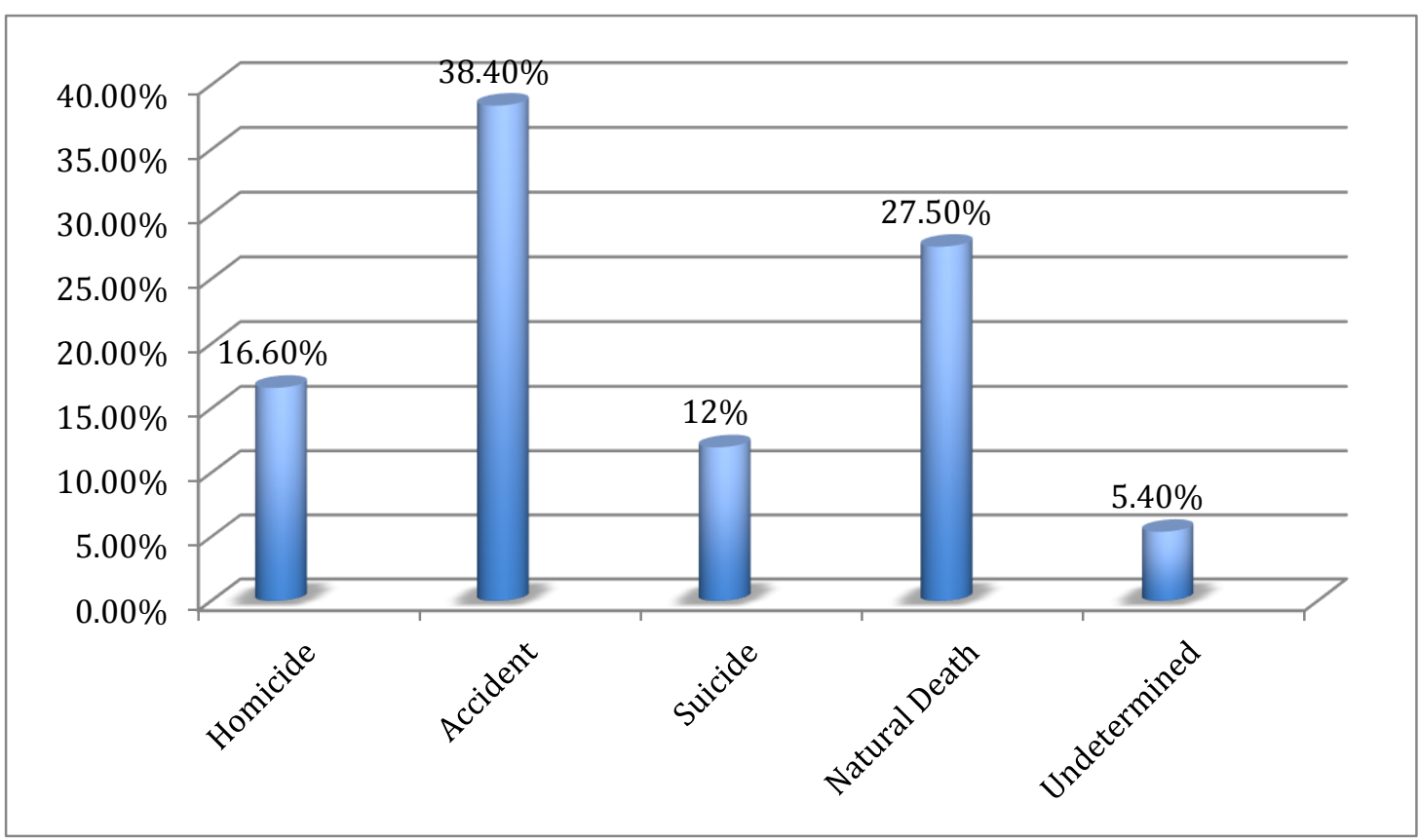

Figure 1. Mode of Death Distribution.

In 1746 (41.5\%), death was in the 16-30 years age group closely followed by 1610 (38.3\%), in the age group of $31-55$ years, $520(12.4 \%)$ and 330 (7.8\%) cases involving age groups of $>56$ years and $<15$ years respectively. Both extremes of age were the least presented. Gender wise male predominated with $74.2 \%$ and females $25.8 \%$, with the male female ratio of 
3:1.The distribution of age is shown in Figure 2 shows the age distribution.

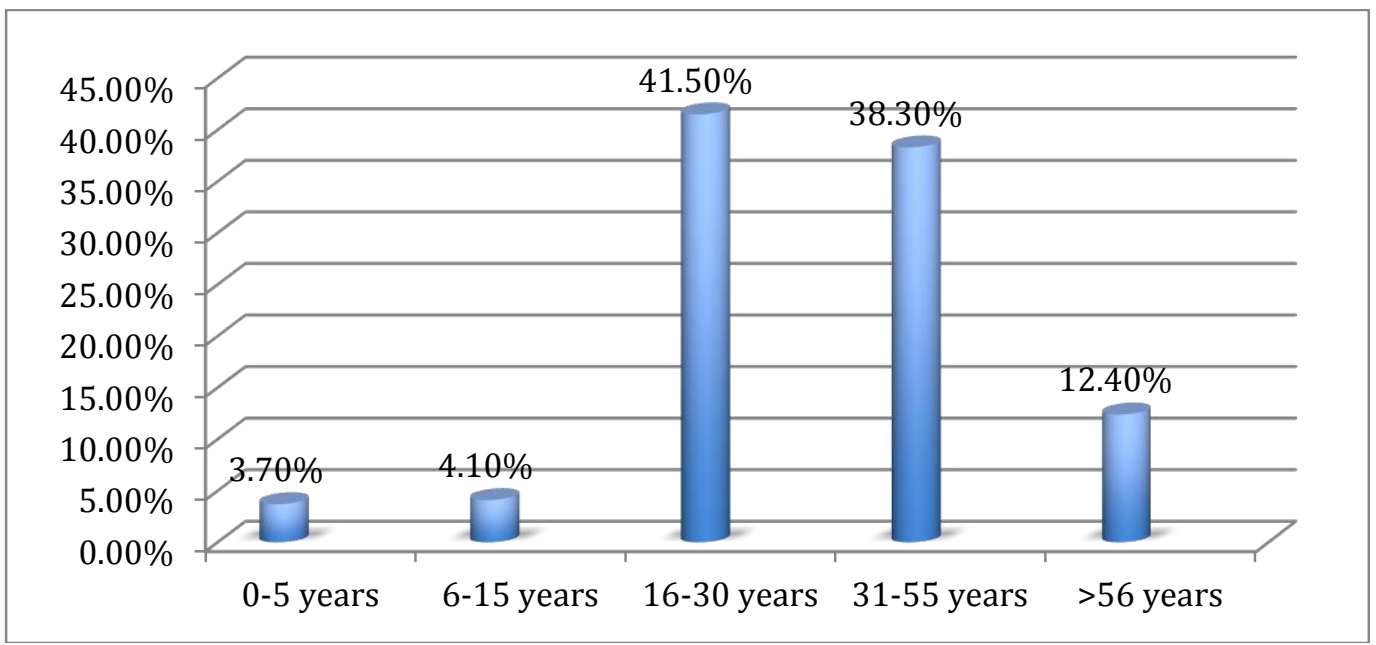

Figure 2. Age-wise Distribution.

Among the 698 deaths due to homicide, blunt weapon injuries accounted for 429 (61.4\%) cases, followed by bullet injury 108 (15.4\%), 101 (14.4\%) deaths by stab injury, strangulation $50(7.5 \%)$, suffocation6 (0.8\%) and others $4(0.5 \%)$ (Figure 3$)$.

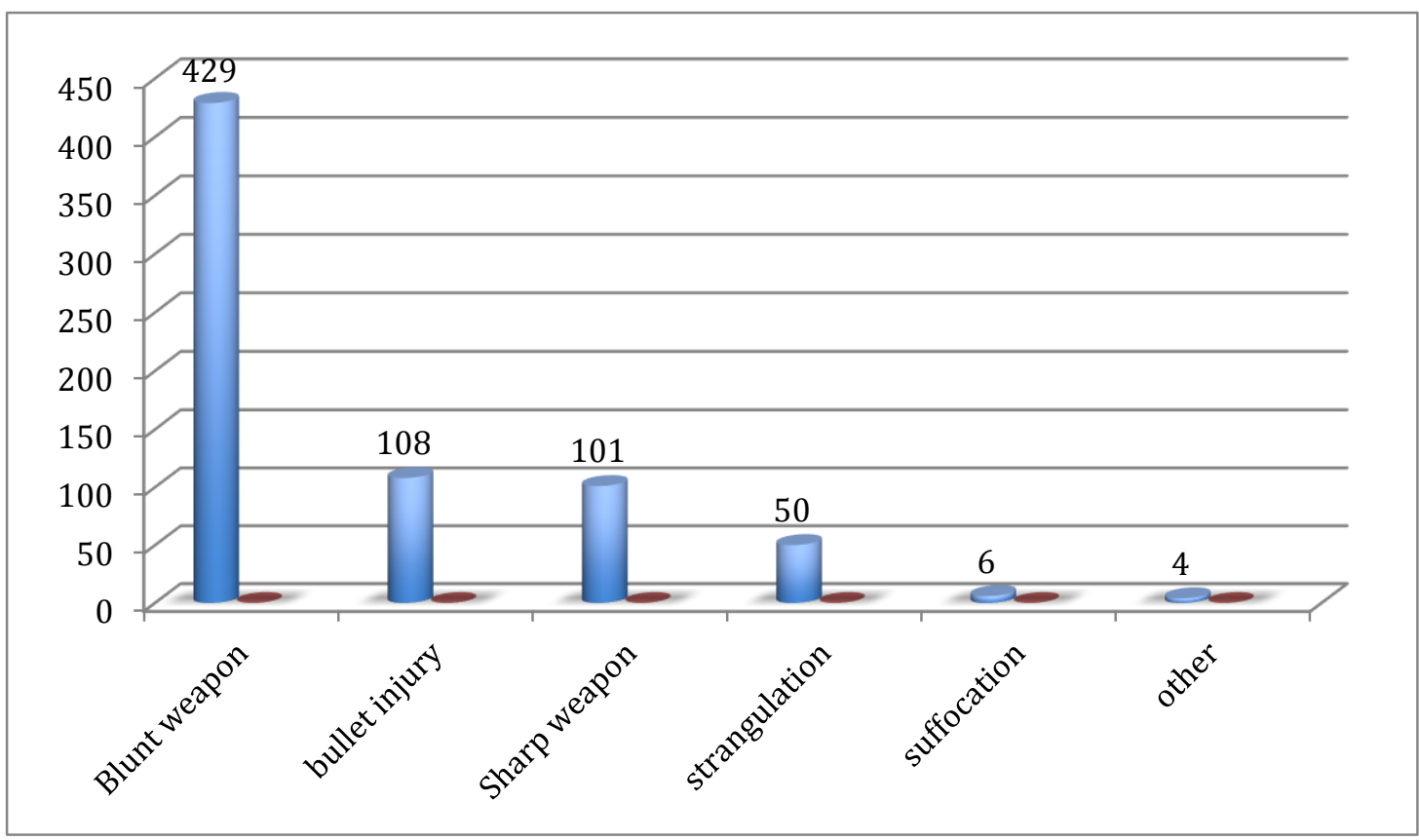

Figure 3. Ditribution of Methods of Homicide

Among 1615 accidents, road traffic accident has been the most commonest type accounting for 1092 (67.6\%), followed by fall accident 170 (10.5\%), drowning 133 (8.5\%), electric accident $108(6.7 \%)$, suffocation $43(2.6 \%)$, intoxication 28 (1.7\%), burn $14(0.8 \%)$ and others 27 (1.6\%) (Figure 4). From 508 suicide cases hanging was the most common modality accounting for $449(88.4 \%)$, followed by poisoning $51(10 \%)$, bullet $4(0.7 \%)$ and others 4 $(0.7 \%)$ (Figure 5). 

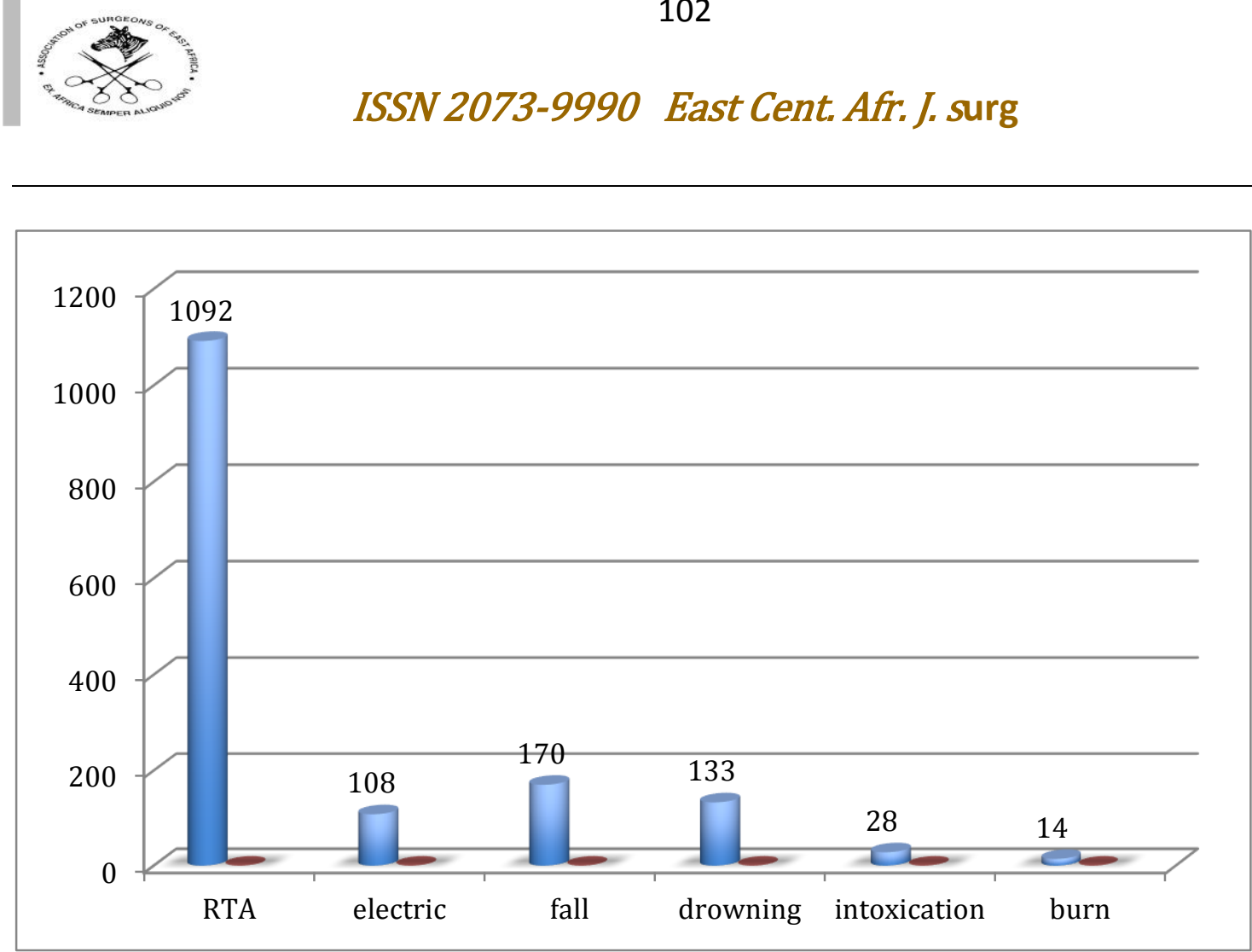

Figure 4. Distribution of Mode of Accidents.

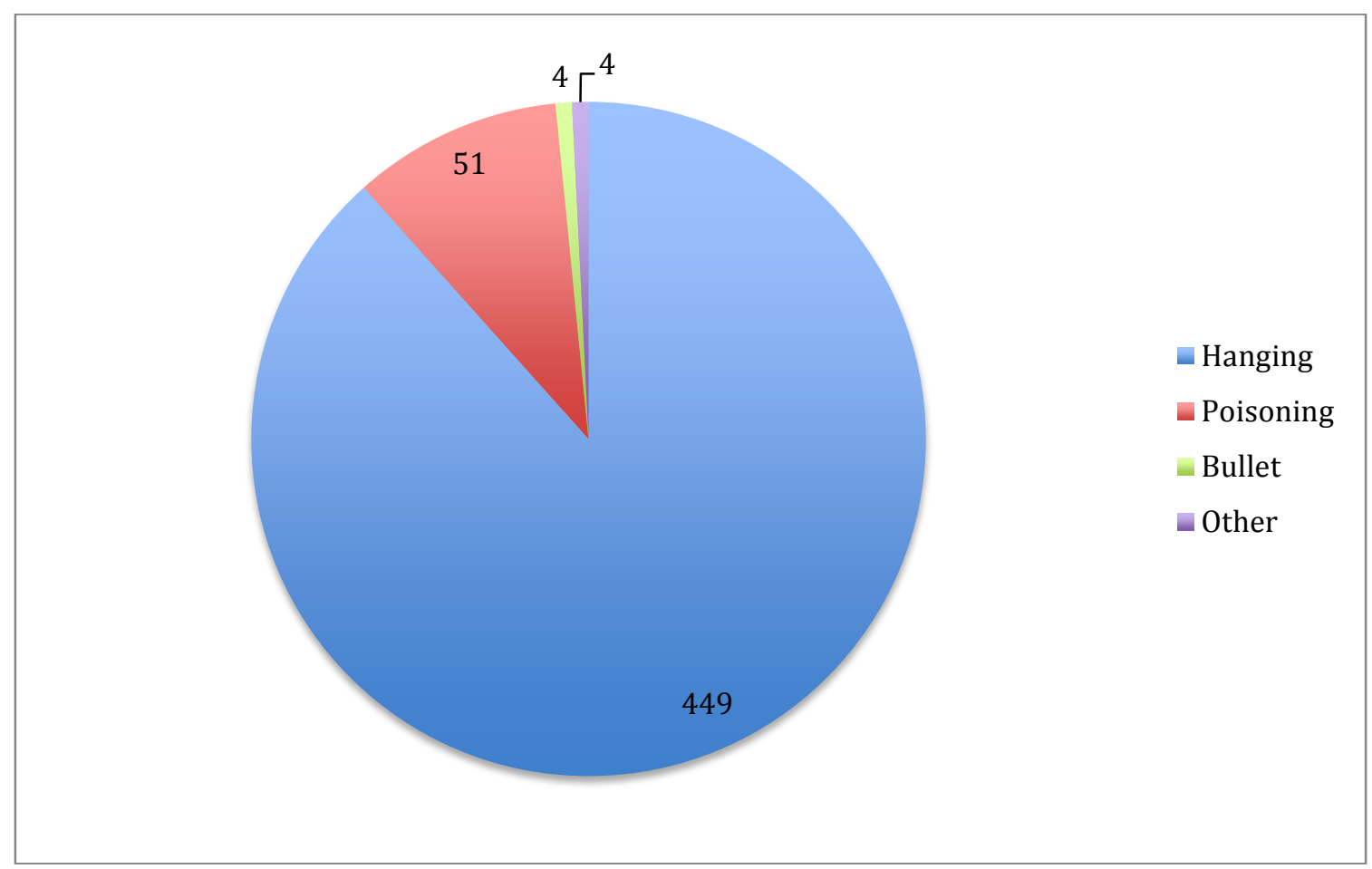

Figure 5. Method of suicide-wise Distribution.

Natural deaths accounted for1190, from this cardiac disease predominated by 453 (38\%), followed by respiratory disease $240(20.2 \%)$, liver and pancreatic disease each accounted for $71(6 \%)$, still birth $27(2.3 \%)$, others 320 (27\%) (Figure 6). 


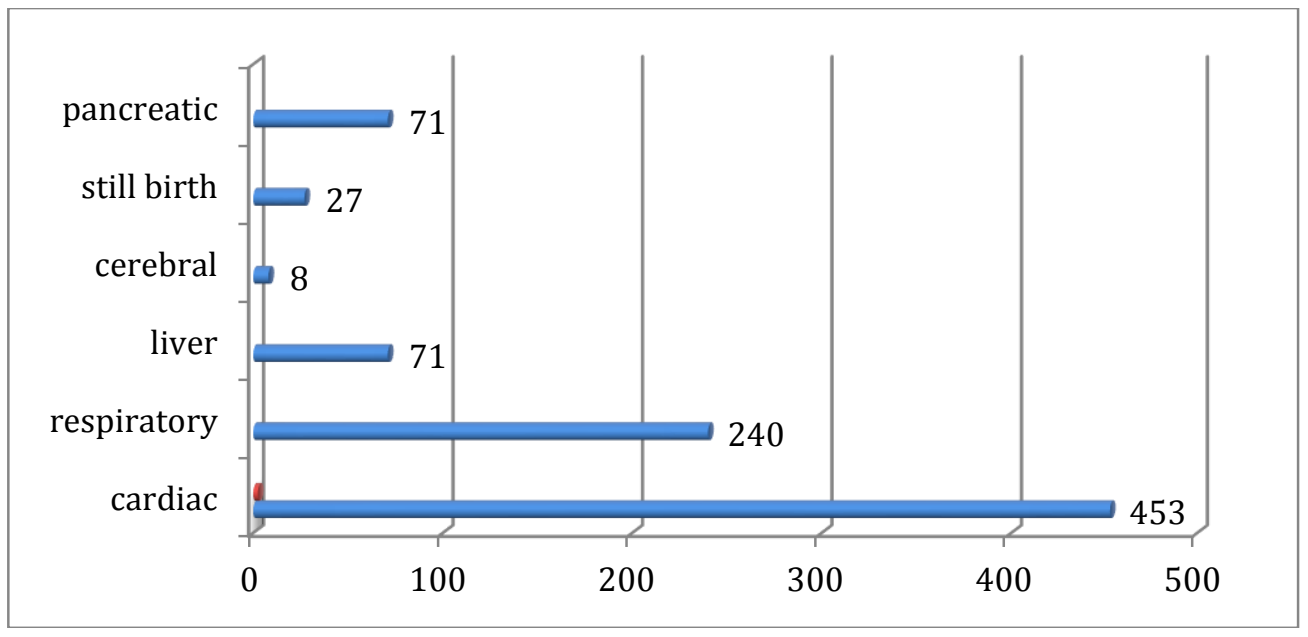

Figure 6. Cause-wise Distribution of Death.

\section{Discussion.}

Out of the total 4206 deaths, 698 (16.6\%) were homicides and 1615 (38.4\%) accidents, while 508 (12\%) were involved in suicidal death. In 1156 (27.7\%) cases, the manner of death was natural, whereas 229 (5.4\%) cases were undetermined (Figure 1). Accidental deaths outnumbered homicidal and suicidal deaths. This finding of present study is in agreement with studies conducted by Rahim ${ }^{5}$ and Ghulam ${ }^{6}$, Akang ${ }^{7}$, Srivastava ${ }^{8}$. In a study done in Nigeria the manner of death are, homicide, natural, accidental and suicide accounting for $40.0 \%, 30.5 \%, 23.8 \%$ and $1.9 \%$ of cases respectively while in $3.81 \%$ of cases the manner of death could not be ascertained ${ }^{25}$. This shows that natural death is the second most common mode of death in both studies, while homicidal death being the leading mode in the Nigerian study and the accidental death being the most prevalent in our study. Kachare et $\mathrm{al}^{10}$ in their study observed that burn (29.41\%) was the commonest cause of death followed by poisoning (24.09) and trauma (21.85\%). In their study $69.40 \%$ cases were of accidental in nature. Other studies Memon ${ }^{12}$, Humayun ${ }^{13}$, Alfaz ${ }^{9}$ which showed homicidal deaths predominance in all unnatural deaths. Pathak et al ${ }^{11}$ observed burns ( $n=216,45.0 \%$ ) as commonest cause of unnatural death in females followed by poisoning. The commonest manner of death in female was accidental $(n=271,56.46 \%)$ followed by suicidal in 141 $(29.37 \%)$ cases with higher incidence of female unnatural death in the age group of 20-29 years $[168(35.0 \%)]$.

In our study road traffic accidents has predominated among the accidental deaths (67.6\%). Other authors have reported similar results, Kumar ${ }^{14}$ reported unnatural death in $88.13 \%$ of total autopsy in relation to population of Varanasi (3676841 according to census 2011) were $0.24 \%$ the unnatural death pattern of road traffic injury $3963(44.11 \%)$ contribute most common cause followed by burn 1911(21.27\%), Poisoning 896 (9.97\%) etc. In our study burn injury has been the least type of accidental injury compared to other studies. In a study conducted in cases of deaths due to road traffic accidents, Govekar et al ${ }^{15}$ observed comparable findings. They observed that road traffic accident deaths are more common. The search for acceleration and speed has lead to the development of high velocity 
motorized vehicles which have become integral part of new system of our modern life ${ }^{10}$.

The most vulnerable age group in our study was $16-30$ years in $41.5 \%$ fatalities, followed by $38.3 \%$ deaths in the $31-55$ years age group. Both extremes of age were the least presented. Pradipkumar Singh et al observed that the age group 21-30 years was the most vulnerable group (24.89\%). Menon et al $^{12}$ reported that the least affected group were those above 70 years ( $2 \%$ and $1 \%$ respectively), which is consistent with the finding in this study. This is due to the fact that persons belonging to the young age group are active, mobile and energetic ${ }^{9}$. The young individuals are short tempered and easily become emotional which result in violence (9) and in addition to this in countries like Ethiopia, the population is relatively young so this could be the reason for this data conclusion.

The male to female ratio of 3:1 in this study is similar to the findings of other authors from other centers ${ }^{5}$. Some other studies have even shown a wider difference between the two genders, like Ghulam et $\mathrm{al}^{6}$ who found a $85.4 \%$ male $(85.4 \%)$ predominance among the victim of unnatural deaths as compared to $14.6 \%$ for females. This could be due to the fact that males are more aggressive and are engaged more in the outdoor activities.

Our study had 698 deaths due to homicide; blunt weapon was the predominant manner, which accounted for $61.4 \%$, followed by bullet injury (15.4). Bhupinder ${ }^{16}$ had similar result to ours and reported that the majority of homicidal deaths were caused by blunt weapon (46\%), followed by sharp weapon (25\%) and asphyxiation (12\%). Despite the decreased rate when compared to our figure, this study is in agreement with our study. In contrast to our study Avnesh ${ }^{17}$ and Hugar ${ }^{18}$ reported sharp weapon injuries as the commonest manner of homicide. Another study done in Chicago from 394 victims $49.5 \%$ were gunshot injury, $27.9 \%$ were sharp weapon injury, $14.7 \%$ were with blunt weapon, and $7.9 \%$ were slain by other means, such as by fire or by being thrown from a building. Shooting was most frequently the means of inflicting death ${ }^{19}$. This difference between studies among countries could be due to influence of the nature of individuals and weapon possession legislation and cultural differences from country to country.

In our study, $12 \%$ of all unnatural deaths were suicides. Hanging was the most common modality accounting for 449 (88.4\%), followed by poisoning $51(10 \%)$. Studies done by Baruah $^{20}$ and Meera ${ }^{21}$ showed that hanging and self-immolation were the most common methods employed for suicide. Whereas Santhosh reported thatthe most common method employed to die were poisoning, hanging, burns and drowning in the decreasing order, which is similarto the study by Behera and colleagues ${ }^{22}$. In a study conducted in Kenya Ingestion of organophosphate poison, hanging and carbon monoxide poisoning were the methods used to commit suicide in order of frequency. There were a total of 195 deaths by organophosphate poisoning, 17 by ligature hanging and only one from carbon monoxide poisoning ${ }^{24}$. Our neighbor country has less rate of suicide by hanging than in our study even if it is the second preferred mode of suicide.In the Nigerian study the suicide rate was as low as $1.9 \%^{25}$.

The leading cause of natural death in our study was cardiovascular disease (38\%) followed 
by respiratory disease (20.2\%). Similar findings have been echoed in studies by Nayak and colleague ${ }^{23}$. Uchendu ${ }^{25}$ reported cardiovascular disease as the predominant cause of natural death, but followed by obstetric and cerebrovascular deaths in contrast to our study. The fact that cardiovascular diseases are becoming the leading cause of death could probably be the western type of life style that our African societies are acquiring.

\section{Conclusion}

Our study concludes that unnatural deaths exceeded enormously the natural deaths. Accident was the most dominant manner of death among the unnatural deaths. Road Traffic Accident was the commonest modality among accidental deaths. Fatalities caused by blunt weapon injuries were the commonest mode of homicide; whereas hanging was the preferred modality of suicide. Cardiovascular diseases were the leading causes of natural deaths. Most deaths are preventable, so concerned bodies are expected to take action of prevention and increase the public awareness of the real situation and the causes of both natural and unnatural deaths and subsequently make an impact in the decrement of death rate in our societies.

\section{References}

1. Pathak A, Sharma S. The study of unnatural female deaths in Vadodara city. J Indian Acad Forensic Med 2010; 32(3): 220-3.

2. Rahim M, Das TC. Mortuary profile for unnatural deaths at Forensic Medicine Department of Dhaka Medical College.Bangl Med J 2009; 38(2): 44-7.

3. Chughtai BR, Iqbal M, Afraz N. Study of Medico-Legal Autopsies at Tehsil Level. J of Rawal Med Coll 2013;17(2):275-6.

4. Marri MZ, Bashir MZ, Arif M, Maqsood M. Analysis of Medico legal Deaths in Sandeman Civil Hospital Quetta, Balochistan. JFJMC 2013;7 (2):13-8.

5. Rahim M, DasTC. Mortuary profile for unnatural deaths at Forensic medicine department of Dhaka Medical college, Bangladesh Medical Journal,Vol.38,No 2 (2009).

6. Ghulam M.Yousfani, Mohammad U. Spectrum of unnatural deaths in Hyderbad:An Autopsy based study. Department of Forensic medicine and Toxicology,Dow University of Health Sciences,Karachi,Pakistan. 2010, Vol.4:54-57.

7. Akang EE, Akinremi T, Oje EM, Oluwasola AO, Ipadeola TO. Pattern of coroners' autopsies at Ring Road State Hospital, Ibadan, Nigeria: a retrospective study (19942000). Med Sci Law 2009; 49(2):117-22.

8. Srivastava P, Som D, Nandy S, Saha I, Pal PB, Ray TG et al. Profile of postmortem cases conducted at a morgue of a tertiary care hospital in Kolkata. J Indian Med Assoc. 2010 Nov; 108(11): 730-3.

9. Alfaz Pervez Qasim, Saeed Akbar Tariq, MohammadNaEEM.profile of unnatural deaths; inFaisalabad.Department of Forensic medicine \&Toxicology.Punjab Medical College, Faisalabad.

10. RV Kachare, Chavan\& et.al; "Analytical study of medico legal deaths in rural region Beed district of Maharashtra"; Journal of Medico legal Association of Maharashtra; 
Dec 2003, Vol.15, No.1-2, Page,14-17.

11. AkhileshPathak\&Shweta Sharma; "The study of unnatural female deaths in Vadodara city"; Journal of Indian Academy of Forensic Medicine: 2010, 32(3) Page, 220-223.

12. Memon MU, Khalil ZH, Aziz K, Kaheri GQ, Khalil IR.Audit of cases autopsied in the Mortuary of Khyber Medical College Peshawar during the year 1999. Annals 2001;7(3):190-3.

Humayun M, Khan D, Zaman F, Khan J, Khan O, Parveen Z, Humayun W. Analysis of Homicidal deaths in District DI Khan: An autopsy study. J Ayub Med CollAbbottabad 2009;21(1):155-7

13. AwdeshKumar, Epidemiological study of unnatural deathpattern in Varanasi, India.International journal of science and Research (IJSR).Vol.3 Issue11, November,2014.

14. GaneshGovekar, Gaurang Patel \& et.al. ; "Trends of road traffic accident in Seurat city": Journal of Indian Academy of Forensic Medicine: 2009, 31(4) Page, 326- 330.

15. Bhupinder S DMJ(Path), Kumara TK BSc, and Syed AM AM 0 Pattern of homicidal deaths autopsied at Penang Hospital, Malaysia, 2007-2009: a preliminary study Department ofForensic Medicine, Penang Hospital, Penang, Malaysia. Malaysian J Pathol 2010; 32(2) : $81-86$

16. Gupta Avneshet al. 2004. - A study of Homicidal Deaths in Delhill, Medicine, Science and Law, 44 (2): 127-132.

17. Basappa S. Hugar, MBBS, MD, DNB, Girish Chandra YP, MBBS, MD, S. Harish, MBBS, MD, DFM, Jayanth SH Pattern of Homicidal Deaths J Indian Acad Forensic Med, 32(3

18. Harwin L. Voss And John R. Hepburn Patterns In Criminal Homicide In Chicago. The Journal of criminal Law.Criminology \& police science.Vol.59, No 4.

19. Baruah AM, Chaliha R. Department of Forensic medicine,Gauhati Medical College. J PanjabAcad Forensic Med Toxicol 2014; 14 (2).

20. Meera T, Singh MBK. Pattern of Neck Findings in Suicidal Hanging .A Study in Manipur . J Indian Acad Forensic Med 2011; 33(4): 352-354

21. Behera A, Balabantry JK, Nayak SR. Review of suicidal cases, A retrospective study. JIAFM 2005: 27(2); 100-102.

22. Nayak GH, BiradarSS, Shivakumar J. Pattern of natural deaths and the frequency of occurrence of diseases that cause them. International Journal of Health Sciences \& Research. 2015; 5(6):313-316.

23. B. N. Macharia, M. A. Iddah, F. M. Ndiangui, and A. KeterPattern of Suicide: A Review of Autopsies Conducted at Moi Teaching and Referral Hospital in Eldoret Kenya The Open Access Journal of Science and Technology Vol. 3 (2015), Article ID 101112, 4 pages doi:10.11131/2015/101112

24. Uchendu OJ. A One Year Review of Autopsies Performed in the Two Major Secondary Health Centers in Benin City. Int. J of Forensic Med Invest 2015; 1:10-14

25. The Russian Red Cross Mission. 